\title{
Protée
}

\section{Une réflexion silencieuse (Travaux de Michelle Héon)}

\section{Michel Groleau}

Volume 28, numéro 2, 2000

Le silence

URI : https://id.erudit.org/iderudit/030593ar

DOI : https://doi.org/10.7202/030593ar

Aller au sommaire du numéro

Éditeur(s)

Département des arts et lettres - Université du Québec à Chicoutimi

ISSN

0300-3523 (imprimé)

1708-2307 (numérique)

Découvrir la revue

Citer cet article

Groleau, M. (2000). Une réflexion silencieuse (Travaux de Michelle Héon).

Protée, 28(2), 47-55. https://doi.org/10.7202/030593ar d'utilisation que vous pouvez consulter en ligne.

https://apropos.erudit.org/fr/usagers/politique-dutilisation/ 


\section{Une réflexion silencieuse}

Michelle Héon s'est intéressée aux environnements et à la topologie dès le

tout début de sa carrière et plus particulièrement, depuis de nombreuses années déjà, à l'archétype de la barque. Ses dernières réalisations portent sur l'interaction entre ses objets et le lieu naturel où l'on retrouve ces archétypes, dont le rivage de la mer, du lac ou de la rivière. Elle a donc mis en scène des installations environnementales où ses barques vieillissent et se dégradent avec le temps. Elle revisite régulièrement ces lieux et prend des photographies de la

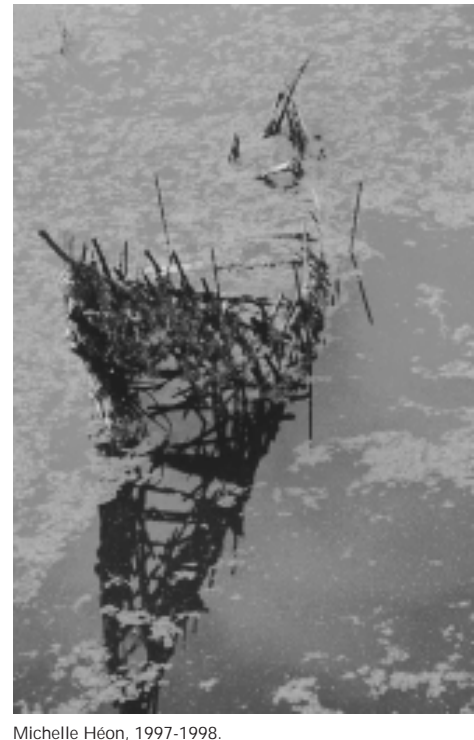
décomposition de l'objet éphémère. L'installation de grandes barques réalisées à Brouage en France fut le début de toute une réflexion silencieuse sur le temps et ses effets pervers, mais combien riches et merveilleux, sur l'objet. Héon reconstruit des lieux imaginaires dans de grands espaces désaffectés où l'eau agit tel un miroir décuplant la présence physique et l'image de I'archétype. Ces lieux sont au départ des lieux de silence puisqu'ils n'ont plus de vie (de raison sociale). Ils sont désertés de toute activité humaine. Leur raison d'être initiale n'est plus valable. Ce sont des lieux que l'on recycle au gré des projets, leur insufflant un nouveau sens. Héon connaît et saisit ces lieux porteurs pour leur redonner vie par le biais de la contemplation. Les jeux de lumière et d'ombres font en sorte que les images que nous percevons ne semblent rien avoir de réel, si ce n'est leur appartenance primaire au réel. Mais Michelle Héon en fait le lieu d'une rencontre ambiguë où se jouxtent une part de réalité et une part d'imaginaire. Le format des œuvres nous plonge non seulement dans le paradoxe, mais aussi dans un espace plus grand que notre échelle humaine, recréant ces grands espaces que nous ne pouvons contenir.

Devant l'immensité, l'H omme a tendance à se taire et à recréer le silence intérieur pour se laisser bercer par la sensation d'une certaine perte d'identité. II se mesure à la démesure et par conséquent confronte sa propre réalité et sa propre longévité.

Michel Groleau 


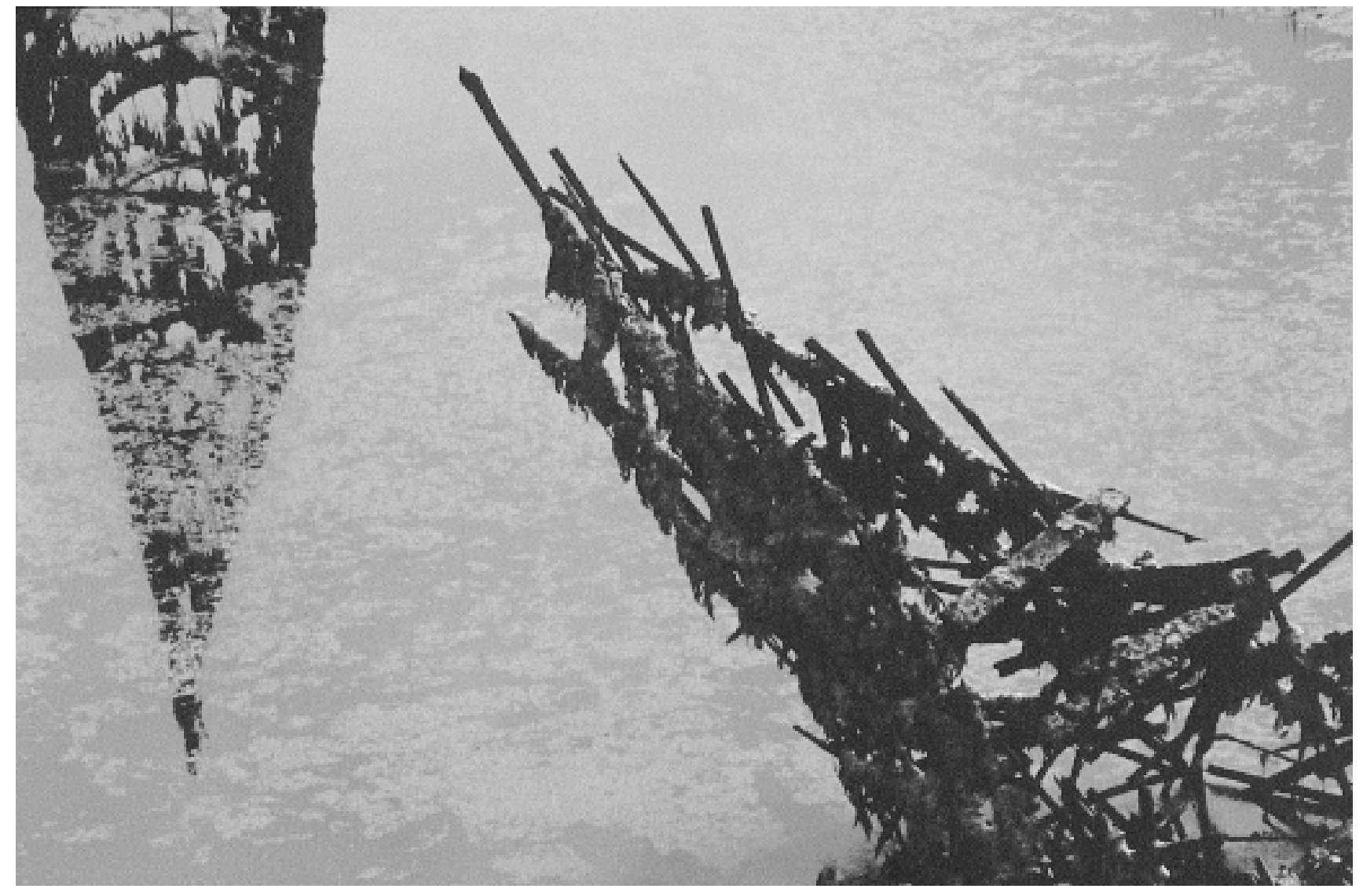

Document photographique (lentilles d'eau vertes), 1999. Recherche photographique/reflets, transformation des éléments du site et des matériaux. Installation à la citadelle de Brouage, France. 


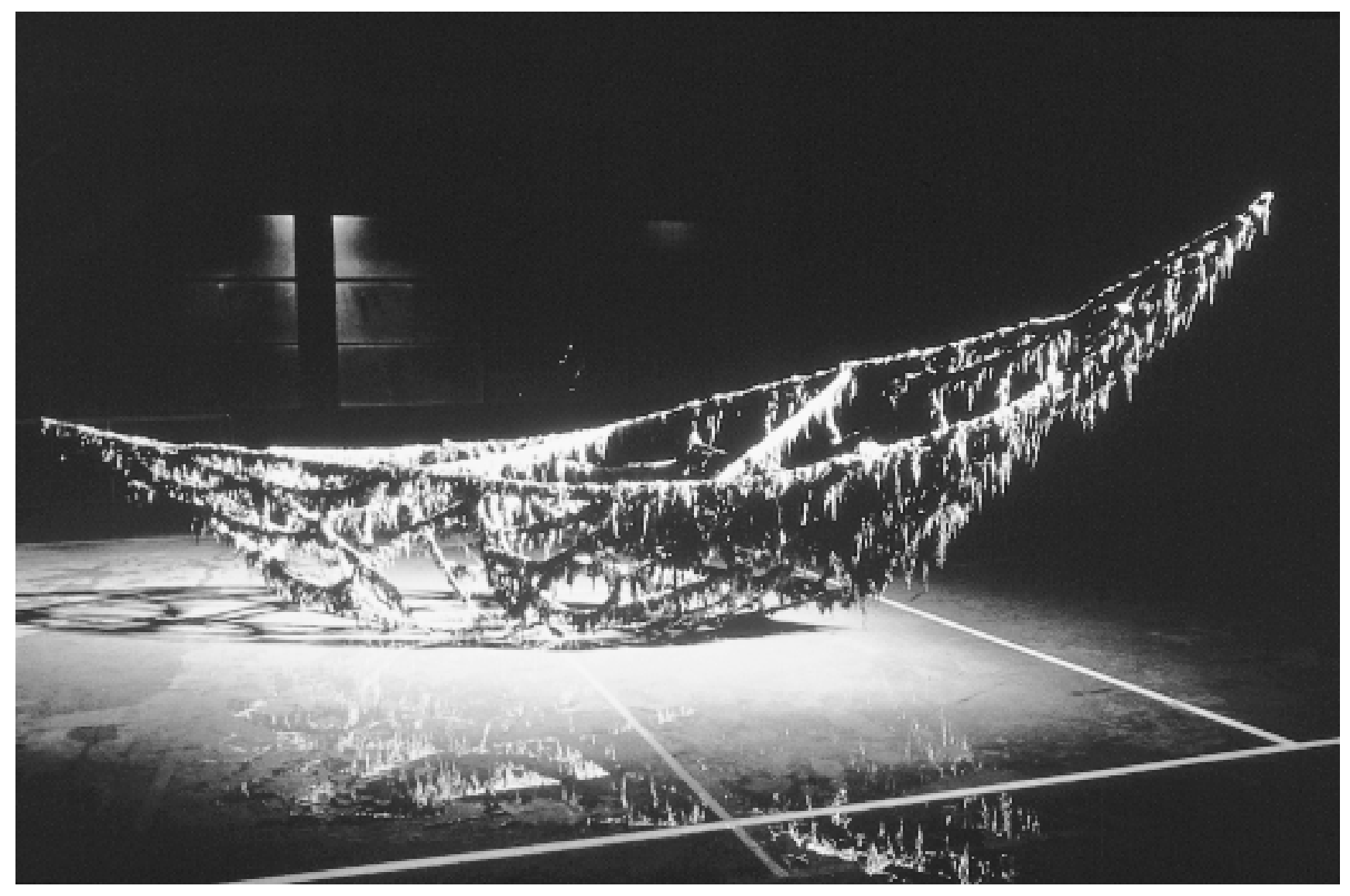

Géographie éphémère, 1999. G rande barque et reflets sur nappe d'eau. U sines Éphémères, M ains d'œuvres, Saint-O uen, France. 


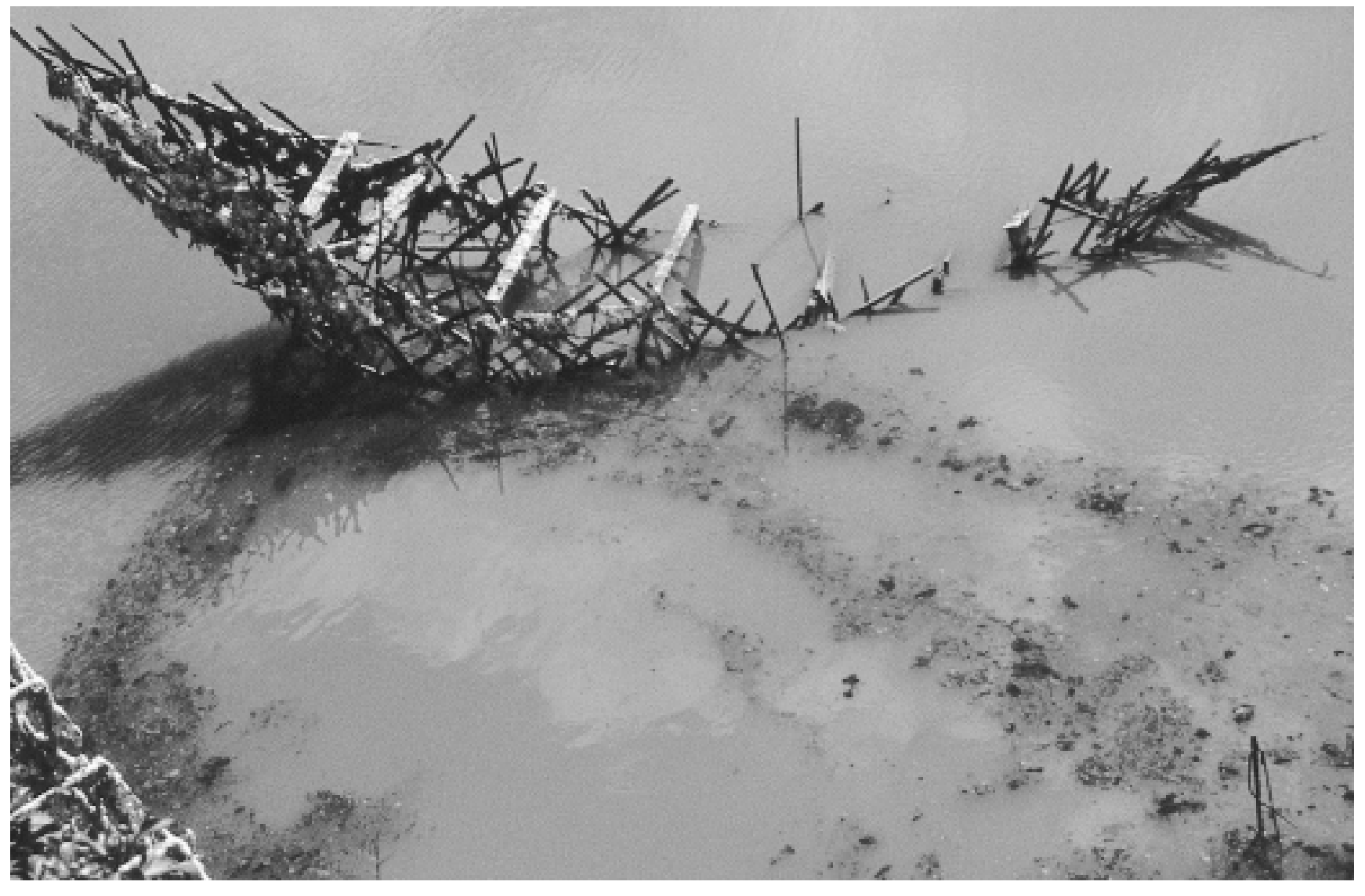

Document photographique (lentilles d'eau rouges), 1999. Recherche photographique/reflets, transformation des éléments du site et des matériaux. Installation à la citadelle de Brouage, France. 


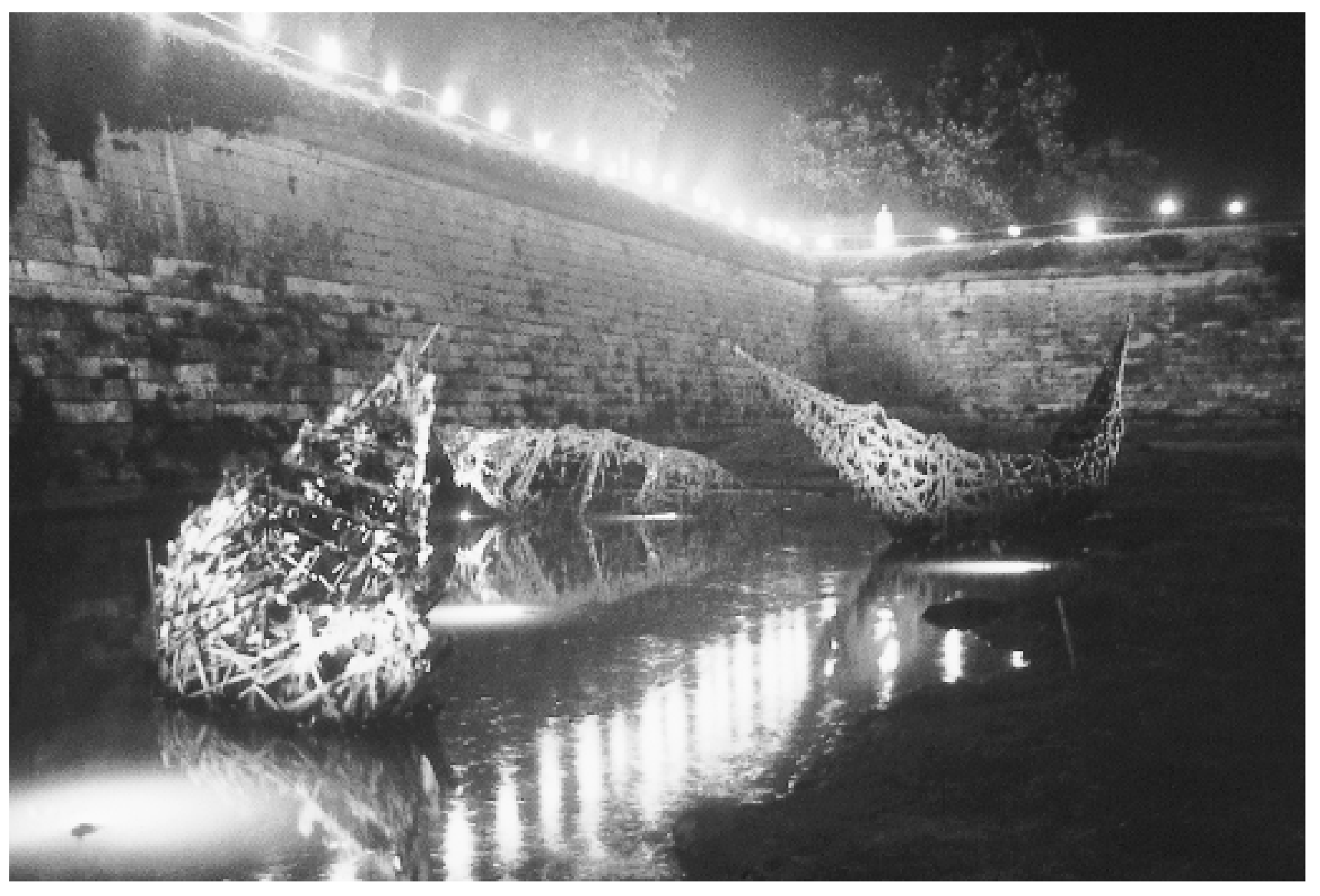

Port de toile (La magie d'un grand site), 1998. Deux barques et trois épaves de $5 \mathrm{~m} \times 6,5 \mathrm{~m}$. Éclairage submersible et hors terre, pots de flamme sur les remparts. Citadelle de Brouage, France. 


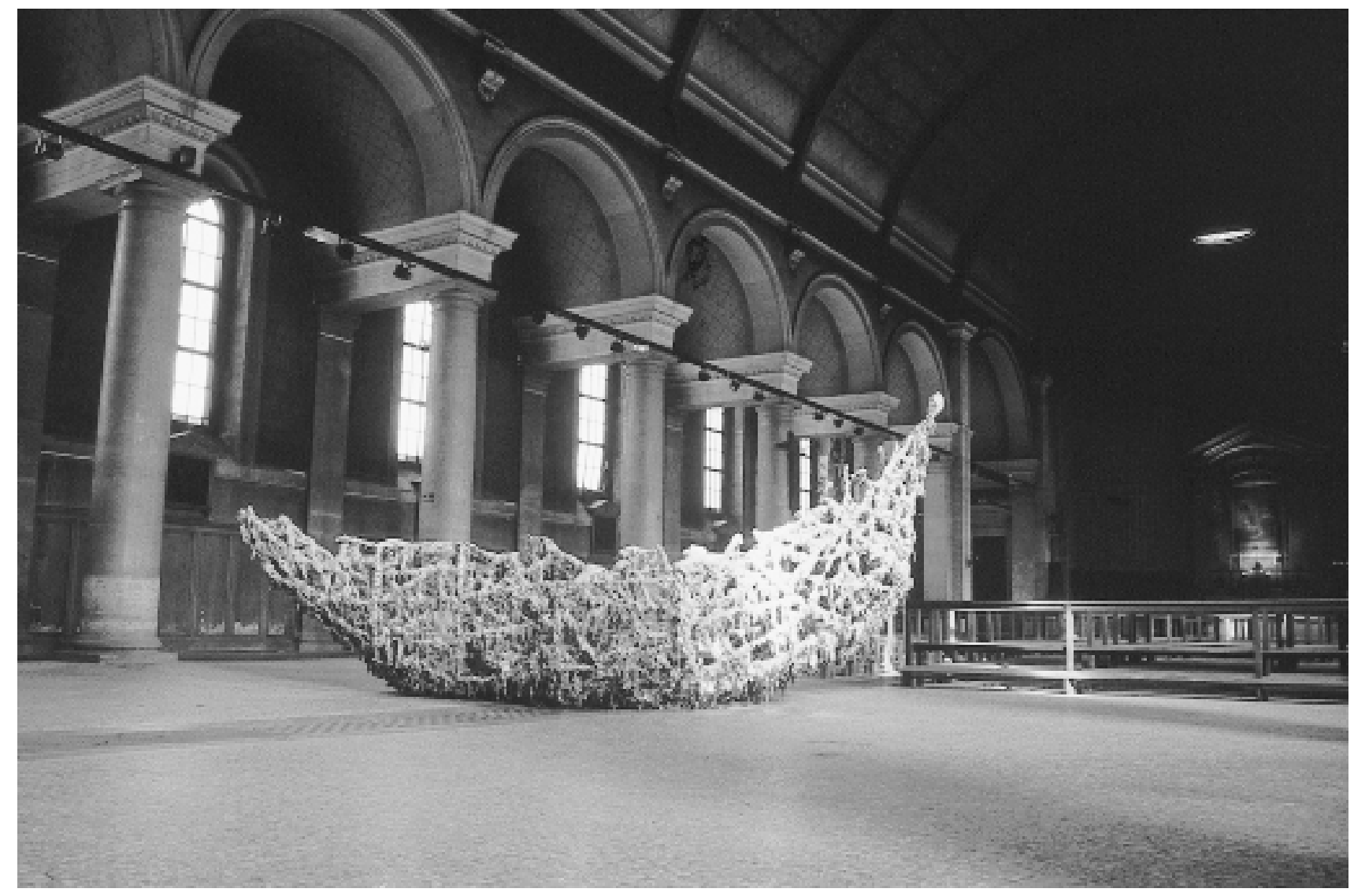

Barque funéraire, 1,65m x 5m x 1,10m, 1995. D raps broyés sur tiges métalliques.

Éclairage : lumière des vitraux captée et réfléchie avec des miroirs. Chapelle de l'hôpital Charles Foix-Edmond Rostand, Yvry-sur-Seine. 


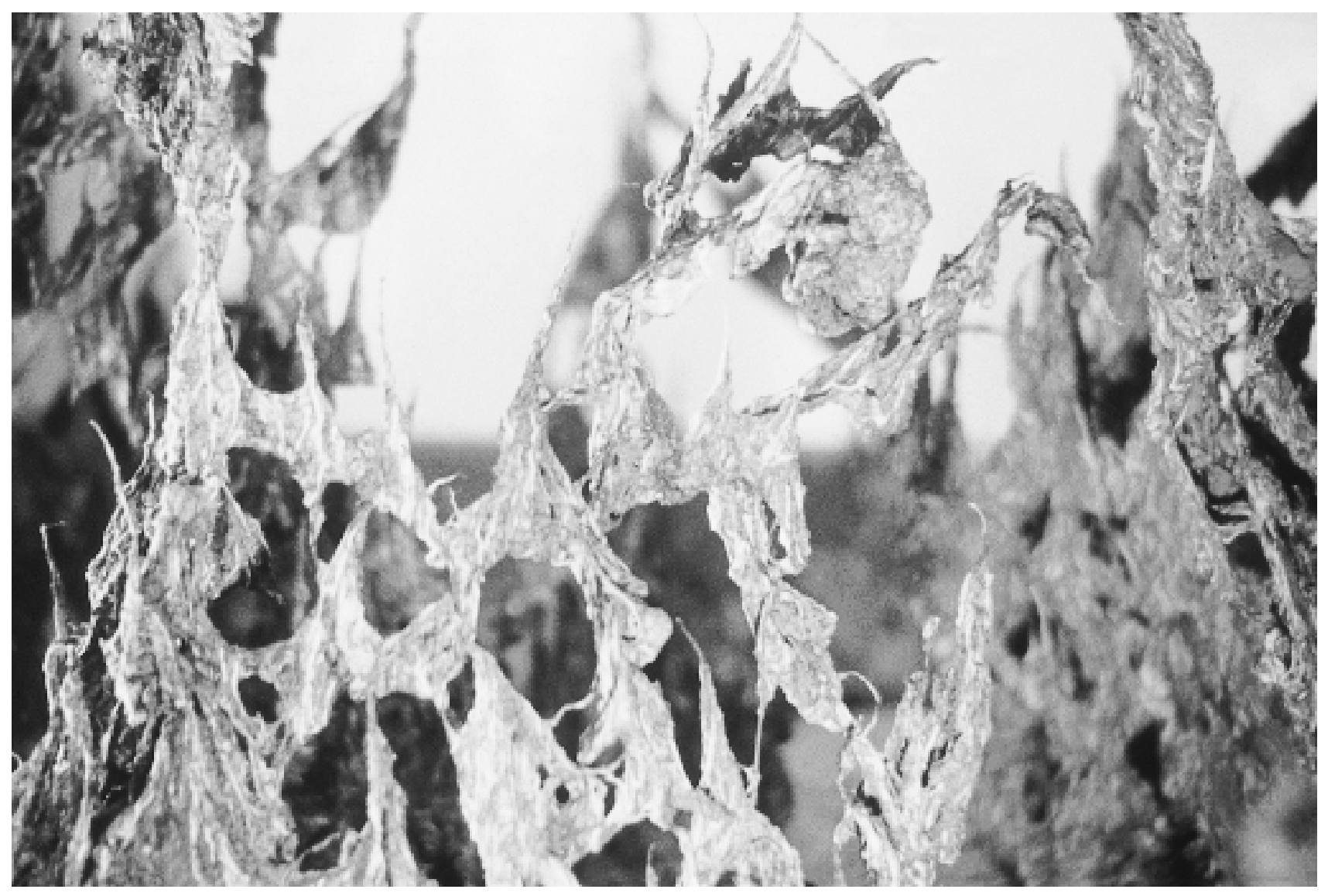

Topologies, $5 \mathrm{~m} \times 7 \mathrm{~m}$ (surface) et $20 \mathrm{~cm}$ à $1,20 \mathrm{~m}$ (hauteur), 1996. Structures de cuivre et de fils d'acier recuit, trempées dans la pâte de denim broyée. Éclairage: néon flexible et lampes de poche. Centre national d'exposition de Jonquière. 


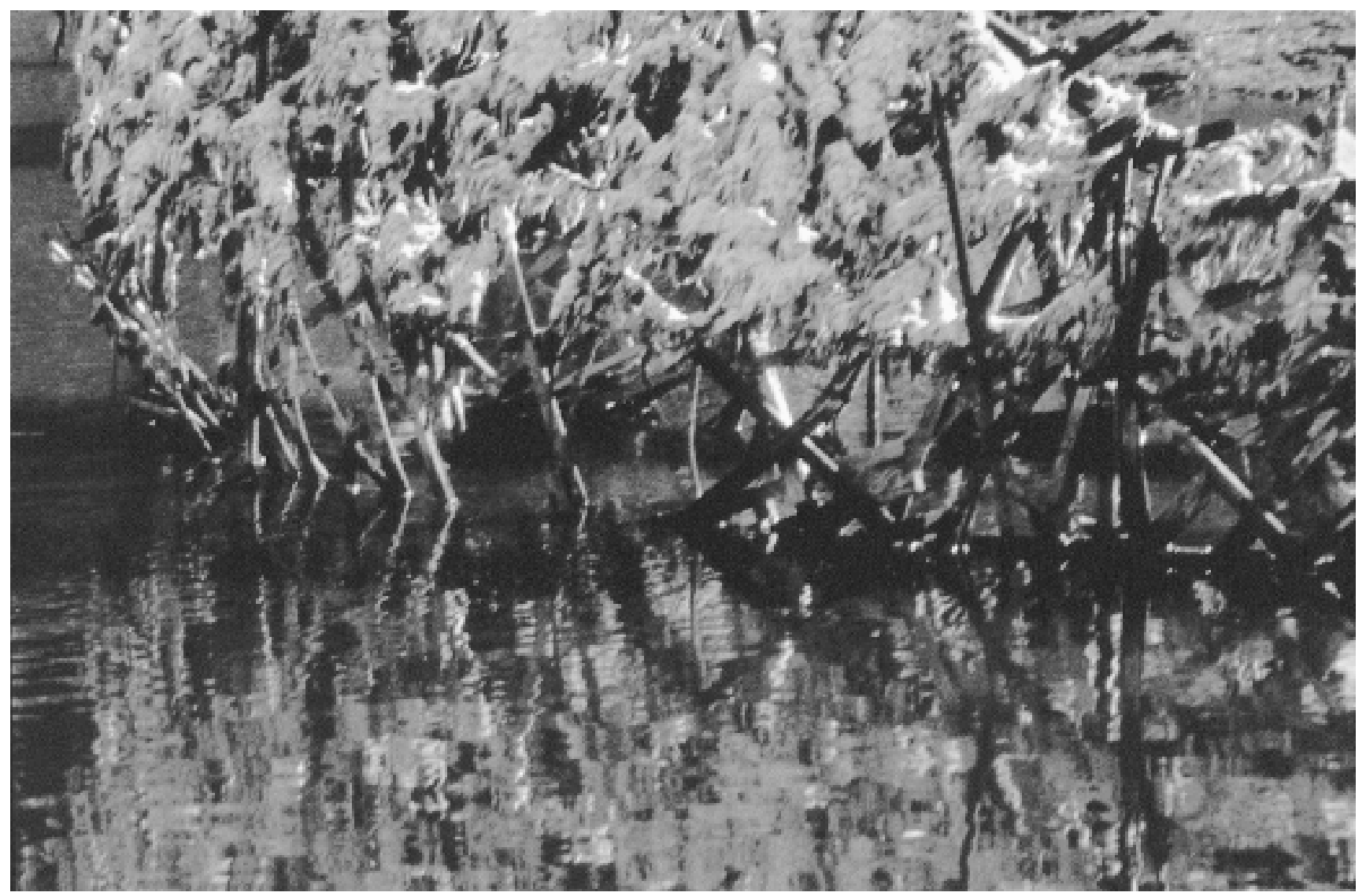

Détail, 1999. Recherche photographique/reflets, transformation des éléments du site et des matériaux. Installation à la citadelle de Brouage, France. 


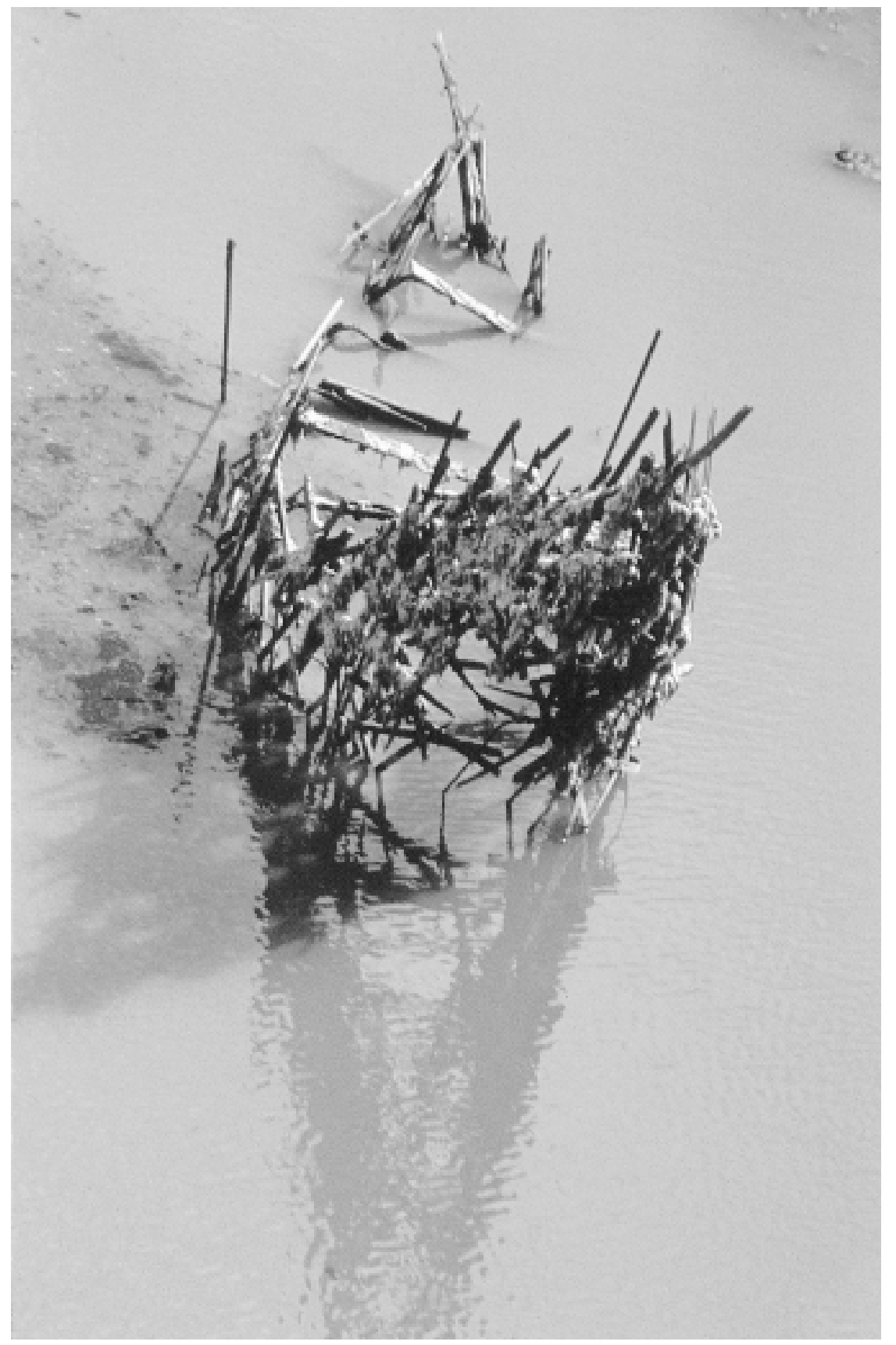

Document photographique (lentilles d'eau rouges), 1999. Recherche photographique/reflets, transformation des éléments du site et des matériaux. Installation à la citadelle de Brouage, France. 